\title{
Early exposure to children in family and day care as related to adult asthma and hay fever: results from the European Community Respiratory Health Survey
}

\author{
C Svanes, D Jarvis, S Chinn, E Omenaas, A Gulsvik, P Burney, for the European \\ Community Respiratory Health Survey
}

Thorax 2002;57:945-950

See end of article for authors' affiliations

Correspondence to:

Dr C Svanes, Department

of Medicine, Haraldsplass

Hospital, 5009 Bergen,

Norway;

cecilie.svanes@

haraldsplass.no

Revised version received 10 July 2002

Accepted for publication

30 July 2002
Background: The literature indicates that early exposure to children in the family and to day care permanently influences the development of allergic disease. A study was undertaken to examine the associations of family size and day care with adult asthma and hay fever and to determine whether these associations are mediated through specific lgE production and whether they vary with allergic predisposition.

Methods: 18530 subjects aged 20-44 years from 36 areas predominantly in the market economies participated in the European Community Respiratory Health Survey and provided information through interviewer-led questionnaires. 13932 subjects gave blood samples for measurement of specific lgE. Results: Hay fever was less common in subjects with many siblings $(O R=0.92 ; 95 \% \mathrm{Cl} 0.90$ to 0.95 per sib). There was a U-shaped relationship between asthma and number of siblings (quadratic effect of siblings, pwheeze $=0.014, \mathrm{pFEV}_{1}=0.016$ ). In subjects without siblings but exposed to children in day care, hay fever was less common $(\mathrm{OR}=0.76 ; 95 \% \mathrm{Cl} 0.60$ to 0.98$)$ and asthma symptoms were more common (ORwheeze=1.48; $95 \% \mathrm{Cl} 1.12$ to 1.95 ). Adjustment for specific lgEs did not alter these associations. The inverse association of hay fever with siblings was found in sensitised subjects $(\mathrm{OR}=0.89 ; 95 \% \mathrm{Cl} 0.84$ to 0.94$)$ and in those with parental allergy $(\mathrm{OR}=0.91 ; 95 \% \mathrm{Cl} 0.85$ to 0.97$)$, but not in subjects without such a predisposition (OR=1.02; $95 \% \mathrm{Cl} 0.97$ to 1.09 ).

Conclusion: Subjects exposed to many children at home or in day care experienced less hay fever and more asthma in adulthood. Microbial challenge through children may contribute to a non-allergic immunological development giving less hay fever but more airways infections predisposing to asthma. These effects were not mediated through production of specific lgE. The protective effect of siblings on hay fever was particularly strong in those with an allergic predisposition. gre

n 1989 Strachan et al ${ }^{1}$ reported less hay fever in adults who grew up in a family with many siblings. One explanation for this finding is the "hygiene hypothesis" which states that close contact with other children early in life presents a microbial challenge which promotes non-allergic immunological maturation. ${ }^{1-4}$ At birth there is a dominance of Th2 immunity. Th2 dominance in utero is believed to be important for a successful outcome of pregnancy, but later in life Th2 immunity is involved with allergic disease. Microbial stimulation after birth is believed to enhance Thl immunity which has an inhibitory action on Th2 immunity. ${ }^{2-4}$ Close contact with children during critical stages of immunological development early in life may thus contribute to an immunological profile that provides permanent protection against allergy.

The negative association between hay fever and family size has consistently been confirmed in the literature. ${ }^{15-9}$ This is also true for sensitisation to common aeroallergens. ${ }^{10-12}$ The literature on exposure to children and asthma is inconsistent, and several reports show non-significant or complex associations between asthma and family size. ${ }^{6} 9^{9}{ }^{13-16}$ Asthma is, however, a disease not only of the immune system but also of the respiratory system. Early life environment may well influence development of the immune system and development of the airways and the lungs in different ways, resulting in complex patterns. Exposure to children in day care should theoretically have the same effect on adult asthma and hay fever as exposure to children in the family, but the literature on this issue is not consistent. In subjects without siblings Krämer et al ${ }^{17}$ reported less hay fever, less diagnosed asthma, and less sensitisation with lower age at the start of day care. Nystad et $a l^{18}$ found more asthma in children who had attended day care, accounted for by more infections in these children. Ball et al ${ }^{19}$ found less hay fever and less wheeze at age 6-13 but more wheeze at age 2 in children who had attended day care.

One might expect that the effect on allergy of exposure to children is mediated through IgE production which is believed to be a central step on the pathway generating allergic symptoms. However, in a report from the British ECRHS the effect of family size on hay fever was not accounted for by the effect on sensitisation. ${ }^{6}$ Further, there is some evidence that the protection against allergy provided by early exposure to children differs with regard to allergic predisposition. In a previous study we found that the protective effect of an increasing number of siblings on adult sensitisation was found only in subjects reporting no parental allergy. ${ }^{10}$

The European Community Respiratory Health Survey stage II contains extensive information on a large number of young adults in 36 different centres in Europe, USA, Australia and New Zealand. Based on these data we have previously published an analysis of adult sensitisation and the association with childhood environmental factors. ${ }^{10}$ In the present study we have assessed the associations between exposure to children in family and day care and the risk for adult hay fever and asthma, while using this large multicentre study in an attempt to explain previous discrepant findings. We have also analysed whether the effect of exposure to children on adult asthma and hay fever is mediated through specific IgE, and whether the effect of exposure to children differs with allergic predisposition. 
Table 1 Prevalence of childhood environmental factors (\%) by country in subjects born between 1945 and 1970

\begin{tabular}{|c|c|c|c|c|c|c|c|c|c|c|c|c|c|c|c|c|c|}
\hline & Iceland & Norway & Sweden & Estonia & Ireland & UK & Neth & Belgium & Germany & Switz & France & Spain & Italy & $\mathrm{NZ}$ & Austr & USA & Total \\
\hline $\mathrm{n}$ & 564 & 835 & 1856 & 431 & 454 & 1579 & 1247 & 1122 & 1983 & 853 & 2125 & 1943 & 894 & 1254 & 668 & 723 & 18530 \\
\hline \multicolumn{18}{|l|}{ No of siblings } \\
\hline 0 & 9 & 5 & 11 & 21 & 3 & 8 & 5 & 11 & 19 & 12 & 13 & 4 & 14 & 5 & 6 & 6 & 10 \\
\hline 1 & 12 & 25 & 36 & 47 & 7 & 32 & 26 & 25 & 39 & 33 & 30 & 24 & 39 & 20 & 28 & 21 & 29 \\
\hline 2 & 26 & 35 & 26 & 21 & 12 & 29 & 25 & 23 & 20 & 26 & 24 & 26 & 25 & 26 & 27 & 26 & 25 \\
\hline 3 & 20 & 20 & 14 & 6 & 15 & 14 & 16 & 15 & 11 & 14 & 15 & 19 & 11 & 19 & 16 & 21 & 15 \\
\hline$\geqslant 4$ & 32 & 15 & 13 & 5 & 62 & 17 & 28 & 26 & 11 & 15 & 19 & 27 & 12 & 30 & 23 & 26 & 21 \\
\hline $\begin{array}{l}\text { Bedroom } \\
\text { sharing* }\end{array}$ & 51 & 49 & 44 & 43 & 70 & 37 & 39 & 39 & 44 & 47 & 41 & 48 & 49 & 42 & 48 & 42 & 44 \\
\hline $\begin{array}{l}\text { Day care } \\
\text { attendance } \dagger\end{array}$ & 28 & 30 & 20 & 45 & 51 & 39 & 79 & 87 & 52 & 28 & 57 & 55 & 60 & 53 & 63 & 30 & 49 \\
\hline $\begin{array}{l}\text { Serious } \\
\text { respiratory } \\
\text { infectionf }\end{array}$ & 11 & 12 & 11 & 15 & 10 & 9 & 7 & 10 & 10 & 11 & 6 & 6 & 10 & 12 & 14 & 10 & 10 \\
\hline
\end{tabular}

* "Did you regularly share your bedroom with any older children before the age of five years?"

†"Did you go to a school, play school, or nursery with any older children before the age of five years?"

f"Did you have a serious respiratory infection before the age of five years?"

\section{METHODS}

\section{Data collection}

The methodology for the ECRHS has been fully described elsewhere. ${ }^{2021}$ Briefly, participating centres selected an area defined by pre-existing administrative boundaries with a population of at least 150000 . Where possible an up to date sampling frame was used to select randomly at least 1500 men and 1500 women aged 20-44 years. In stage I subjects were sent the ECRHS screening questionnaire, a self-completed questionnaire asking about symptoms suggestive of asthma, the use of medication for asthma, and the presence of hay fever or nasal allergies. In stage II a random sample of subjects who had completed the screening questionnaire was invited to attend for a more detailed interviewer-led questionnaire, lung function testing, and blood tests. Data for 18530 subjects from 36 centres in 16 countries were included. Informed consent was obtained from all participants and the study was approved by all the ethics committees involved.

The questions from the interviewer-led questionnaire used in this analysis are given as footnotes to tables 1 and 2. Questions about asthma symptoms that did not include the word "asthma" were used as outcome variables, as diagnosing asthma in subjects with respiratory symptoms is dependent on the presence or absence of atopy ${ }^{22}$ according to traditions that vary between countries.

Specific IgE to house dust mite, cat, timothy grass and Cladosporium was measured in serum samples obtained by centrifugation of $10 \mathrm{ml}$ whole blood at $4000 \mathrm{~g}$ for 10 minutes. All samples were stored at $-20^{\circ} \mathrm{C}$ and analysed in a central laboratory by the CAP system, (Pharmacia Diagnostics, Sweden) except for samples from Melbourne which were analysed locally using the same analytical technique. The test for specific IgE was considered to be positive if values of $>0.35 \mathrm{kU} / \mathrm{l}$ (the lowest detection limit of the assay) were obtained. The distribution of serum IgE for all but one of the centres included in the study has been described previously. ${ }^{23}$ Of the 18530 subjects included in the study, 13932 (75\%) provided a blood sample. "Atopy" was defined as specific IgE to cat, grass, house dust mite, and/or mould. The association of childhood environmental factors and atopy in this population has been described in a previous paper. ${ }^{10}$

Forced expiratory volume in 1 second $\left(\mathrm{FEV}_{1}\right)$ and forced vital capacity (FVC) were recorded by a standard spirometric method $^{24}$ and the ratio between FEV $\mathrm{F}_{1}$ and FVC was calculated. Percentage predicted $\mathrm{FEV}_{1}$ was calculated by the formula from the European Community for Steel and Coal. ${ }^{25}$ Methacholine challenge was performed using a dosimeter (Mefar, Brescia, Italy) and the degree of bronchial responsiveness (BHR) was expressed as the ECRHS slope. ${ }^{26}$ Height was measured before measurement of lung function.

\section{Statistical analysis}

Logistic regression models were used to assess the independent effects of the childhood exposure variables (number of siblings, bedroom sharing, day care attendance, and serious respiratory infection; questions given in footnote to table 1 ) on symptoms of asthma, hay fever, and eczema (questions given in footnote to table 2). Multiple linear regression models were used to assess the independent effects of the childhood exposure variables on lung function and bronchial responsiveness. The number of siblings was categorised as $0,1,2,3$, and 4 or more or entered as a continuous variable. A U-shaped distribution of asthma symptoms and lung function measures with number of siblings was revealed by analyses of categorised data and fitted into models using a continuous plus a quadratic effect of siblings. In all analyses adjustments were made for sex, age, parental smoking (paternal smoking, maternal smoking, maternal smoking in pregnancy), adult smoking habits (never, ex-smoker, current smoker), current occupation (European Economic Community status groups $14)^{27}$ and study centre. Potential heterogeneity between centres in the effect of each exposure variable on asthma and on hay fever was studied by meta-analyses according to DerSimonian and Laird. ${ }^{28}$ Analyses of day care were stratified by presence of siblings, and analyses of siblings and hay fever were stratified by allergic predisposition (atopy, parental allergy). Stratification by sex did not reveal differences in the associations of symptoms of allergic disease with exposure to children (data not given). All analyses were carried out using the statistical software program Stata 5.0.

\section{RESULTS}

Sibships were relatively large in Ireland and small in Estonia, otherwise there were relatively small differences between countries with regard to family size (table 1). Attendance at day care before the age of 5 varied greatly from $20 \%$ in Sweden to $87 \%$ in Belgium.

Mutually adjusted estimates for associations of family size, bedroom sharing, day care attendance, and serious respiratory infections with symptoms are presented in table 2. Hay fever and eczema consistently decreased with increasing number of siblings. Bedroom sharing and day care attendance before the age of 5 years were not significantly related to symptoms after adjustment for other factors in the total sample. Asthma symptoms were more common in subjects who reported severe respiratory infections before the age of 5 . The increased risk for hay fever and eczema related to severe respiratory infections was slightly attenuated but still statistically significant after adjustment for wheeze.

Asthma symptoms were related to family size in a non-linear pattern, with an initial decrease and a subsequent 


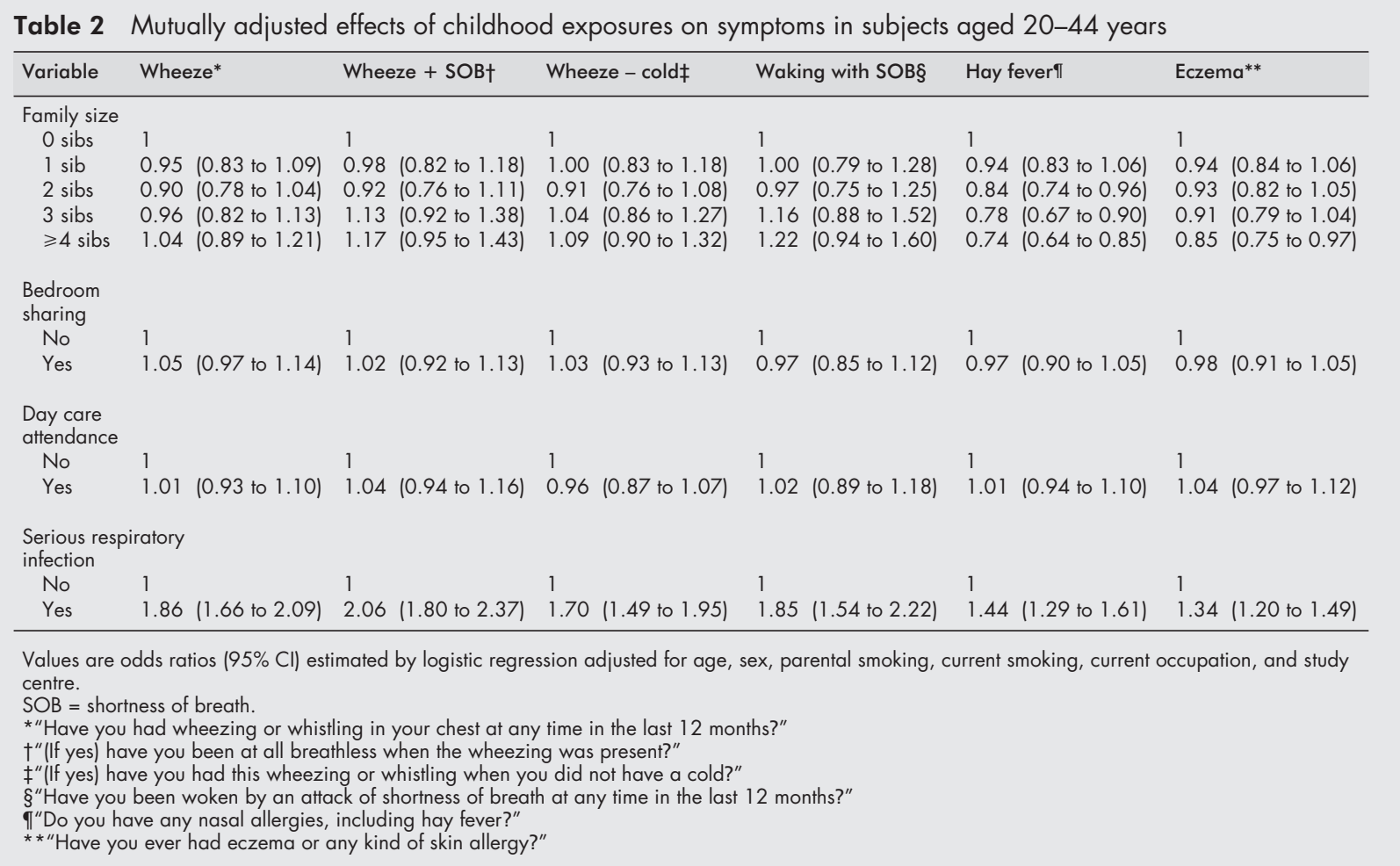

Table 3 Day care attendance before age 5 and association with allergic disease in adulthood in subjects with and without siblings

\begin{tabular}{|c|c|c|c|c|c|c|}
\hline & \multirow[b]{2}{*}{ Day care } & \multicolumn{2}{|c|}{ Subjects with no siblings } & \multicolumn{2}{|l|}{ Subjects with siblings } & \multirow{2}{*}{$\begin{array}{l}p \text { value for } \\
\text { interactiont }\end{array}$} \\
\hline & & $\mathrm{N}$ symptoms/total* & OR $(95 \% \mathrm{Cl}) \dagger$ & N symptoms/total* & OR $(95 \% \mathrm{Cl}) \dagger$ & \\
\hline \multirow[t]{2}{*}{ Wheeze } & No & $164 / 812$ & 1 & $1844 / 7996$ & 1 & \\
\hline & Yes & $230 / 946$ & $1.48(1.12$ to 1.95$)$ & $1827 / 8012$ & $0.97(0.89$ to 1.06$)$ & 0.025 \\
\hline \multirow[t]{2}{*}{ Wheeze + SOB } & No & $78 / 809$ & 1 & $899 / 7981$ & 1 & \\
\hline & Yes & $113 / 945$ & 1.33 (0.92 to 1.92$)$ & $949 / 8001$ & $1.02(0.91$ to 1.14$)$ & NS \\
\hline \multirow[t]{2}{*}{ Wheeze - cold } & No & $100 / 808$ & 1 & $1103 / 7976$ & 1 & \\
\hline & Yes & $129 / 944$ & $1.26(0.90$ to 1.76$)$ & $1067 / 7997$ & 0.94 (0.84 to 1.04$)$ & NS \\
\hline \multirow[t]{2}{*}{ Hay fever } & No & $252 / 811$ & 1 & $2069 / 7980$ & 1 & \\
\hline & Yes & $253 / 944$ & $0.76(0.60$ to 0.98$)$ & $2122 / 7998$ & 1.05 (0.97 to 1.14$)$ & 0.043 \\
\hline \multirow[t]{2}{*}{ Eczema } & No & $335 / 811$ & 1 & $3106 / 7991$ & 1 & \\
\hline & Yes & $378 / 946$ & 1.08 (0.86 to 1.36$)$ & $2975 / 8002$ & 1.04 (0.96 to 1.12$)$ & NS \\
\hline
\end{tabular}

*For each question some subjects answered "don't know", hence the totals are not 18530.

†Estimated by logistic regression adjusted for number of siblings, bedroom sharing, serious respiratory infections, sex, age, parental smoking, current smoking, current occupation, and centre.

increase in risk with increasing number of siblings (table 2). This U-shaped relation as a quadratic effect of siblings was statistically significant (pwheeze $=0.014$ ). When analysed using two siblings as the baseline category, having more than two siblings was significantly related to increased risk for asthma symptoms (ORwheeze $=1.12$ (95\% CI 1.01 to 1.23 ); ORwheeze with SOB $=1.25$ (95\% CI 1.10 to 1.42 ); ORwheeze without cold $=1.17$ (95\% CI 1.04 to 1.32 ); ORwaking with $\mathrm{SOB}=1.23(95 \%$ CI 1.04 to 1.46$))$. Having less than two siblings was related to a slight non-significant increase in risk for asthma symptoms (odds ratios ranging from 1.03 to 1.10). When atopic asthma (symptoms plus atopy) and non-atopic asthma (symptoms but no atopy) were analysed as separate outcome variables, a U-shaped association with the number of siblings was pronounced and highly significant for non-atopic asthma while atopic asthma showed no significant association with the number of siblings, although a U-shaped effect was indicated.

In subjects with no siblings day care attendance was associated with a reduced risk for hay fever but an increased risk for asthma symptoms (table 3). Day care was not associated with symptoms in subjects with siblings. The associations of day care with hay fever and wheeze were significantly different for those with and without siblings. No such interaction was indicated for eczema, for which there was no association with day care in those with or without siblings.

The association of hay fever with number of siblings was not accounted for by atopy (defined as specific IgE to grass, cat, house dust mite, and/or mould). Adjustment for atopy or specific IgE to grass did not attenuate the effect of having siblings on hay fever (adjustment for atopy: ORwheeze $=0.93$ 
Table 4 Association between number of siblings and adult hay fever according to atopic status (serum specific lgE to grass, cat, house dust mite and/or mould) and parental allergy (mother and/or father having eczema, skin/nasal allergy, or hay fever ever).

\begin{tabular}{|c|c|c|c|c|}
\hline $\begin{array}{l}\text { Subgroups according to increasing number of } \\
\text { predisposing factors }\end{array}$ & No* & No (\%) with hay fever & OR $(95 \% \mathrm{Cl}) \dagger$ per sibling & $p$ value \\
\hline No atopy, no parental allergy & 6852 & $839(12 \%)$ & 1.02 (0.97 to 1.09 ) & NS \\
\hline No atopy, parental allergy & 2508 & $603(24 \%)$ & 0.91 (0.84 to 0.99$)$ & 0.028 \\
\hline Atopy, no parental allergy & 2908 & $1176(40 \%)$ & 0.92 (0.86 to 0.98$)$ & 0.007 \\
\hline Atopy, parental allergy & 1581 & $1021(64 \%)$ & $0.88(0.80$ to 0.96$)$ & 0.006 \\
\hline All & 17676 & $4840(27 \%)$ & $0.92(0.90$ to 0.95$)$ & $<0.001$ \\
\hline
\end{tabular}

* Of 18530 subjects who provided questionnaire information, 13932 provided blood tests for lgE analyses and some data are missing for each variable. Thus, the totals of the individual rows does not equal the final total.

†Estimated by logistic regression adjusted for number of siblings, bedroom sharing, serious respiratory infections, sex, age, current smoking, current occupation, and centre.

(95\% CI 0.90 to 0.97$)$, adjustment for IgE grass: ORwheeze $=0.93(95 \%$ CI 0.89 to 0.96$))$. An association between the number of siblings and hay fever was only found in subjects with atopy and/or parental allergy (table 4). The association between family size and hay fever was significantly different in atopic and non-atopic subjects $(\mathrm{p}<0.001)$ and, within the non-atopic subjects, between those with and without parental allergy $(p=0.006)$. A protective effect of siblings on hay fever was found for both brothers and sisters also when adjusting for atopy and in atopic subjects considered separately (data not given).

Adjustment for atopy or parental allergy did not alter the U-shaped association between asthma symptoms and number of siblings. Stratification by atopy, parental asthma, parental allergy, and smoking consistently gave a U-shaped pattern in all subgroups with two exceptions: (1) there was no association between asthma symptoms and the number of siblings in subjects reporting parental asthma, and (2) there was no initial decrease in risk (two siblings compared with none or one sibling) in non-atopic subjects with no history of parental allergy. The effects of brothers and sisters on risk for asthma symptoms were similar when adjusting for atopy, an additional protective effect of brothers on asthma symptoms was accounted for by a protective effect of brothers on atopy (described in a previous analysis of atopy ${ }^{10}$ ).

Meta-analyses performed for the associations of all childhood exposures with wheeze and with hay fever showed no significant heterogeneity between centres.

There was a significant U-shaped relationship between number of siblings and $\mathrm{FEV}_{1}$ and $\mathrm{FVC}$ with an initial increase in lung function from zero to one or two siblings (positive linear effect of siblings $\mathrm{pFEV}_{1}=0.09$; $\mathrm{pFVC}=0.1$ ) and a subsequent decrease in lung function with a larger number of siblings (negative quadratic effect of siblings $\mathrm{pFEV}_{1}=0.016$; $\mathrm{pFVC}=0.035$ ). There were no significant associations between the number of siblings and the $\mathrm{FEV}_{1} / \mathrm{FVC}$ ratio or BHR. When BHR with and without atopy was analysed separately, a U-shaped association between number of siblings and non-atopic BHR was of borderline significance while no association was indicated for atopic BHR. FEV ${ }_{1}$ was significantly higher in subjects who had attended day care, independent of the number of siblings. In subjects reporting serious respiratory infections in childhood, lung function$\left(\mathrm{FEV}_{1}, \mathrm{FVC}\right.$, and $\mathrm{FEV}_{1} / \mathrm{FVC}$ ratio) was significantly reduced and BHR significantly increased.

\section{DISCUSSION}

Childhood exposure to other children in the family or in day care was associated with less hay fever and more asthma symptoms in young adults. The consistency of the associations with both family size and with day care (in subjects with no siblings) suggests that early exposure to other children is the factor of importance rather than the sociocultural effects of family size or day care. This view is supported by the consistency of the findings across centres with varying rates of day care attendance, varying family sizes, and varying socioeconomic conditions.

The particular strength of this study, apart from the large number of subjects, was the ability to compare findings between 36 socioculturally, genetically, and geographically different centres across the western world. One limitation of the study was the retrospectively collected information about childhood environmental factors. The information on childhood respiratory infection is likely to be biased and is therefore not used for major conclusions but for a minor argument in the discussion. The number of siblings was the most important exposure variable and is not likely to be affected by recall bias. Information about childhood day care attendance as given by adults may be imprecise, but an error in recall is not likely to be systematic with regard to adult asthma or hay fever. The question on day care referred to attendance before the age of 5 years which, for the purpose of this paper, is rather imprecise although easier to recall. These problems will probably tend to attenuate rather than to produce associations with adult allergic symptoms. The tendency towards better lung function in subjects who attended day care suggests that these children were healthier, but this needs to be assessed by longitudinal analyses.

The observation of less hay fever in subjects exposed to other children in the family or in day care is in agreement with previous studies. ${ }^{15-791719}$ A suggested explanation for this association is the "hygiene hypothesis", ${ }^{1-4}$ the theory that the microbial stimulation in childhood provided by contact with other children may contribute to a non-allergic immunological maturation. In agreement with Krämer et al, ${ }^{17}$ we found a "protective" effect of day care on hay fever only in subjects without siblings. This suggests that the effect of exposure to children is not dose dependent; in children who are already exposed to children in the family, exposure to more children in day care provides no further "protection". The effect of siblings on hay fever appears to be dose related. However, this increased "protection" with increasing number of siblings could reflect a higher probability of receiving the hypothesised immunological stimulation during the sensitive age window.

The effect of siblings and day care attendance on hay fever was not mediated through atopic sensitisation. Adjustment for atopy, for number of positive specific IgEs, for the individual specific IgEs separately, or for the level of each specific IgE hardly altered the effect of siblings on hay fever. Furthermore, within the group of atopic subjects there was a strong inverse association between number of siblings and hay fever. The general belief has been that the microbial challenge represented by number of siblings contributes to a Thl stimulation that downregulates IgE responses and thereby leads to less allergic disease. Our findings indicate that production of specific IgE antibodies is not the link between Thl stimulation (if this is what contact with other children represents) and 
lack of allergic symptoms. Atopy could be a marker of a group with high risk for allergic responses, but within this group other factors could determine whether the individual develops allergic symptoms or not.

The association between the number of siblings and hay fever was observed only in individuals with an allergic disposition-that is, serologically measured atopy or parental allergy. We have previously reported that the presence of specific IgE is related to the number of siblings only in subjects with no parental allergy. ${ }^{10}$ Both these interactions were statistically significant and consistent to different methods of analysis. The strong genetic predisposition for IgE production in subjects with parental allergy might be inherited independent of microbial stimulation, while such stimulation could inhibit development of IgE immunity in subjects with a less strong genetic predisposition. With regard to symptoms, however, microbial stimulation could be particularly important in subjects who already have signs of a poor Thl cell development (indicated by atopy or parental allergy). ${ }^{4}$ In subjects with no parental allergy and no atopy the Thl cell function may be satisfactory ${ }^{4}$ and additional microbial stimulation from siblings not necessary.

A U-shaped association was found between number of siblings and asthma. Although complicated, this pattern was consistent for lung function as well as symptoms and was consistent between different methods of analysis and homogeneous across centres. The increase in asthma risk in subjects with many siblings was supported by an increase in risk in subjects exposed to many children in day care. As opposed to the very consistent findings in the literature with regard to family size and atopic sensitisation ${ }^{10-12}$ or hay fever, ${ }^{1}\left[5[6]^{7-9}\right.$ the literature on exposure to children and asthma is inconsistent. There are reports of a protective effect of siblings on asthma, ${ }^{6}{ }^{14}$ including a report from the British centres of the ECRHS, ${ }^{6}$ but most studies show inconsistent, nonsignificant or complex associations between asthma and family size. ${ }^{79^{13} 1516}$ Similarly, the literature on day care attendance and asthma gives inconsistent findings. ${ }^{17-19}$ The discrepancies in the literature regarding early exposure to children and asthma could be related to different definitions of asthma, particularly with regard to concomitant allergy, ${ }^{22}$ to asthma being a heterogeneous disease (a disease not only of the immune system but also of the respiratory system), and to problems in ascertaining timing of exposure. As our analysis showed a U-shaped association between asthma symptoms and number of siblings, differences in family size between countries and age groups may also contribute to discrepant observations. In countries or time periods with mostly small families, no trend or indication of a "protective" effect may be observed, while in a society with larger families an increase in risk with many siblings may be revealed.

Microbial burden could possibly explain why those from larger families experience both more asthma and less hay fever. While microbial stimulation during a sensitive stage of immunological development may enhance a non-allergic immunological maturation, this same microbial challenge could also lead to more clinically manifest airways infections, some of which could permanently damage the structure of the lungs. At ages when the immunological profile is already determined, harmful clinical infections may possibly be the only effect of microbial stimulation. An association between severe lower airways infections early in life and adult obstructive lung disease is well documented. ${ }^{29}{ }^{30}$ The increase in asthma among children who attended day care in the study of Nystad et $a l^{18}$ was accounted for by more respiratory infections. Although we could not confirm this in our study population, our data on infections are crude. The decrease in asthma symptoms for subjects with one or two siblings might be explained by some protective effect of microbial stimulation, as this effect was only found in subjects with a high predisposition to allergy (as also observed for hay fever). Confounding by birth weight seems unlikely because asthma symptoms were related to total number of siblings rather than birth order.

One apparent paradox of the "hygiene hypothesis" is that no study convincingly shows a direct protective effect of clinical infections on allergic disease. In particular, no study shows a protective effect of respiratory tract infections on allergic disease, even if such infections represent a considerable microbial burden. Bacterial colonisation of the respiratory and gastrointestinal mucosa may possibly provide immunological stimulation of Thl immunity without necessarily causing clinical infections. ${ }^{23}$ In agreement with other studies, ${ }^{131}$ our study shows not only more asthma, but also more hay fever and eczema related to clinically manifest infections in childhood. Prescott et al ${ }^{4}$ showed poor Thl immunity as well as boosting of the Th2 response in allergic infants, suggesting a generally poor Th cell function in these subjects. One might speculate whether the Thl response to microbial stimulation in allergic subjects could be sufficient to induce some Th2 inhibition but insufficient in the defence against certain pathogenic microbes, rendering allergic subjects liable to more severe clinical infections.

In conclusion, exposure to many children at home or in day care was related to less hay fever and more asthma in adulthood. The microbial challenge that other children represent might contribute to non-allergic immunological development and, at the same time, to more clinical infections including lower airways infections adversely affecting the lungs. The increase in asthma and reduction in hay fever on exposure to other children was not mediated through changes in atopic sensitisation, questioning whether production of specific IgE is the only step on the pathway between deviation of immune responses through early microbial stimulation and the modulation of symptoms of allergic disease. Exposure to siblings led to a reduction in reported hay fever only in subjects with atopy or parental allergy. The microbial stimulation from other children could possibly be of greater importance in preventing allergic symptoms in subjects with impaired Th cell function.

\section{ACKNOWLEDGEMENTS}

The coordination of this work was supported by the European Commission and we are grateful to the late Colette Baya and Dr Manuel Hallen for their help during the study and to Professor K Vuylsteek and the members of the COMAC for their support.

\section{Authors' affiliations}

C Svanes, E Omenaas, A Gulsvik, Department of Thoracic Medicine, University of Bergen, 5021 Bergen, Norway

D Jarvis, S Chinn, P Burney, Department of Public Health Sciences,

King's College London, London SE 13 QD, UK

Coordinating centre (London): P Burney, S Chinn, C Luczynska, D Jarvis, E Lai.

Project Management Group: P Burney (project leader), S Chinn, C Luczynska, D Jarvis, P Vermeire (Antwerp), H Kesteloot (Leuven), J Bousquet (Montpellier), D Nowak (Hamburg), the late J Prichard (Dublin), R de Marco (Verona), B Rijcken (Groningen), J M Anto (Barcelona), J Alves (Oporto), G Boman (Uppsala), N Nielsen (Copenhagen), P Paoletti (Pisa).

Participating centres: Austria: W Popp (Vienna); Australia: M Abramson, J Raven, J Rolland (Melbourne);Belgium: P Vermeire, F van Bastelaer (Antwerp South, Antwerp Central); Estonia: R Jögi (Tartu); France: J Bousquet, J Knani (Montpellier), F Neukirch, R Liard (Paris), I Pin, C Pison (Grenoble), A Taytard (Bordeaux); Germany: H Magnussen, D Nowak (Hamburg), H E Wichmann, J Heinrich (Erfurt); Greece: N Papageorgiou, P Avarlis, M Gaga, C Marossis (Athens); Iceland: T Gislason, D Gislason (Reykjavik); Ireland: J Prichard, S Allwright, D Macleod (Dublin); Italy: M Bugiani, C Bucca, C Romano (Turin), R de Marco Lo Cascio, C Campello (Verona), A Marinoni, I Cerveri, L Casali (Pavia); Netherlands: B Rijcken, A Kremer (Groningen, Bergen-op-Zoom, Geleen); New Zealand: J Crane, S Lewis (Wellington, Christchurch, Hawkes Bay); Norway: A Gulsvik, E Omenaas (Bergen); Portugal: J A Marques, J Alves (Oporto); Spain: J M Antó, J Sunyer, 
F Burgos, J Castellsagué, J Roca, J B Soriano, A Tobías (Barcelona), N Muniozguren, J Ramos González, A Capelastegui (Galdakao), J Castillo, J Rodriguez Portal (Seville), J Martinez-Moratalla, E Almar (Albacete), J Maldonado Pérez A Pereira, J Sánchez (Huelva), J Quiros, I Huerta, F Pavo (Oviedo); Sweden: G Boman, C Janson, E Björnsson (Uppsala), L Rosenhall, E Norrman, B Lundbäck (Umeå), N Lindholm, P Plaschke (Göteborg); Switzerland: U Ackermann-Liebrich, N Künzli, A Perruchoud (Basel); UK: M Burr, J Layzell (Caerphilly), R Hall (Ipswich), B Harrison (Norwich), J Stark (Cambridge); USA: S Buist, W Vollmer, M Osborne (Portland).

The following grants helped to fund the local studies: Australia: Allen and Hanbury's, Australia; Belgium: Belgian Science Policy Office, National Fund for Scientific Research; France: Ministère de la Santé, Glaxo France, Institut Pneumologique d'Aquitaine, Contrat de Plan Etat-Région Languedoc-Rousillon, CNMATS, CNMRT (90MR/10, 91 AF/6), Ministre delegué de la santé, RNSP; Germany: GSF and the Bundesminister für Forschung und Technologie, Bonn; Greece: Greek Secretary General of Research and Technology, Fisons, Astra and Boehringer-Ingelheim; India: Bombay Hospital Trust; Italy: Ministero dell'Università e della Ricerca Scientifica e Tecnologica, CNR, Regione Veneto grant RSF $\mathrm{n}$. 381/05.93; New Zealand: Asthma Foundation of New Zealand, Lotteries Grant Board, Health Research Council of New Zealand; Norway: Norwegian Research Council project no 101422/310; Portugal: Glaxo Farmacêutica Lda, Sandoz Portugesa; Spain: Ministero Sanidad y Consumo FIS grants \#91/0016060/00E-05E and \#93/0393 and grants from Hospital General de Albacete, Hospital General Juan Ramón Jiménenz, Consejeria de Sanidad Principado de Asturias; Sweden: Swedish Medical Research Council, Swedish Heart Lung Foundation, Swedish Association against Asthma and Allergy; Switzerland: Swiss National Science Foundation grant 4026-28099; UK: National Asthma Campaign, British Lung Foundation, Department of Health, South Thames Regional Health Authority; USA: United States Department of Health, Education and Welfare Public Health Service grant \#2 S07 RR05521-28.

\section{REFERENCES}

1 Strachan DP. Hay fever, hygiene and household size. BM 1989;299: 1259-60.

2 Björksten B. Allergy priming early in life. Lancet 1999;353:167.

3 Martinez FD, Holt PG. Role of microbial burden in aetiology of allergy and asthma. Lancet 1999;354:SII12-5.

4 Prescott SL, Macaubas C, Smallacombe T, et al. Development of allergen-specific T-cell memory in atopic and normal children. Lancet 1999;353:196-200

5 Strachan DP, Harkins LS, Golding J, and the ALSPAC Study Team. Sibship size and self-reported inhalant allergy among adult women. Clin Exp Allergy 1997;27:151-5.

6 Jarvis D, Chinn S, Luczynska C, et al. The association of family size with atopy and atopic disease. Clin Exp Allergy 1997;27:240-5

7 Bråbäck L, Hedberg A. Perinatal risk factors for atopic disease in conscripts. Clin Exp Allergy 1998;28:936-42.

8 Strachan DP, Taylor EM, Carpenter RG. Family structure, neonatal infection, and hay fever in adolescence. Arch Dis Child 1996;74:422-6.

9 Räsänen $M$, Laitinen T, Kaprio J, et al. Hay fever, asthma and number of older siblings: a twin study. Clin Exp Allergy 1997;27:515-8.
10 Svanes C, Jarvis D, Chinn S. et al. on behalf of the European Community Respiratory Health Survey. Childhood environment and adult atopy: Results from the European Community Respiratory Health Survey. J Allergy Clin Immunol 1999;103:415-20.

11 Strachan DP, Harkins LS, Johnston IDA, et al. Childhood antecedents of allergic sensitisation in young British adults. J Allergy Clin Immunol 1997;99:6-12.

12 von Mutius E, Martinez F, Fritzsch C, et al. Skin test reactivity and number of siblings. BM 1994;308:692-5.

13 Bodner C, Godden D, Seaton A. Family size, childhood infection and atopic diseases. Thorax 1998;53:28-32.

14 Rona RJ, Duran-Tauleria E, Chinn S. Family size, atopic disorders in parents, asthma in children, and ethinicity. J Allergy Clin Immunol 1997;99:454-60.

15 Rona RJ, Hughes JM, Chinn S. Association between asthma and family size between 1977 and 1994. J Epidemiol Community Health 1999;53:15-19.

16 Strachan DP, Butland BK, Anderson HR. Incidence and prognosis of asthma and wheezing illness from early childhood to age 33 in a national British cohort. BM 1996;312:1195-9.

17 Krämer U, Heinrich J, Wist $M$, et al. Age of entry to day nursery and allergy in later childhood. Lancet 1999;353:450-4.

18 Nystad W, Skrondal A, Magnus P. Day care attendance, recurrent respiratory tract infections and asthma. Int J Epidemiol 1999;28:882-7.

19 Ball TM, Castro-Rodriguez JA, Griffith KA, et al. Siblings, day-care attendance, and the risk of asthma and wheezing during childhood. N Engl J Med 2000;343:538-43

20 Burney PGJ, Luczynska C, Chinn S, et al. The European Community Respiratory Health Survey. Eur Respir J 1994;7:954-60.

21 European Community Respiratory Health Survey. Medicine and Health EC Directorate General XIII. Luxembourg: Office for Official Publications, 1994.

22 Svanes C, Omenaas E, Eide GE, et al. Hospitalisation for lung disease in early childhood and asthma symptoms in young adults. Respir Med 1998;92:1003-9

23 Burney P, Malmberg E, Chinn S, et al. The distribution of total and specific serum IgE in the European Community Respiratory Health Survey. J Allergy Clin Immunol 1997;99:314-22.

24 Roca R, Burgos F, Sunyer J, et al. Reference values for forced spirometry. Eur Respir J 1998;11:1354-62.

25 European Commnunity for Coal and Steel. Standardisation of lung function tests. Clin Respir Physiol 1983;19(Suppl 5):22-7.

26 Chinn S, Burney $P$, Jarvis $D$, et al. Variation in bronchial hyperresponsiveness in the European Community Respiratory Health Survey. Eur Respir J 1997; 10:2495-501.

27 Office of Population Censuses and Surveys. Classification of occupations. London: HMSO, 1980.

28 DerSimonian R, Laird N. Meta-analysis in clinical trials. Control Clin Trials 1986;7:177-88

29 Barker DJP, Godfrey KM, Fall C, et al. Relation of birth weight and childhood respiratory infection to adult lung function and death from chronic obstructive airways disease. BM 1991;303:671-5.

30 Shaheen SO, Barker DJP, Shiell AW, et al. The relationship between pneumonia in early childhood and impaired lung function in late adult life. Am J Respir Crit Care Med 1994;149:616-9.

31 von Mutius E, Illi S, Hirsch T, et al. Frequency of infections and risk of asthma, atopy and airway hyperresponsiveness in children. Eur Respir J 1999; 14:4-11. 